\title{
FIRST DRAFT OF WOCE Plan Under ReVIEW
}

\section{Although}

it represents

some of the best

thinking of the

several dozen

oceanographers

involved in the

U.S. planning

effort over the

last five years,

the plan is still

in draft form.
$\mathrm{T}_{\mathrm{r}}$ he first draft of a document describing the proposed U.S. contributions to the World Ocean Circulation Experiment (WOCE) was distributed in May for review and comment within the oceanographic community in the United States.

This draft Implementation Plan describes the WOCE research efforts contemplated by U.S. scientists, discusses how these activities will mesh with other projects launched by other nations, and makes a first estimate at what the programs will cost. Although it represents some of the best thinking of the several dozen oceanographers involved in the U.S. planning effort over the last five years, the plan is still in draft form. The U.S. WOCE Planning Office at Texas A\&M University has mailed the plan to more than 500 scientists around the country in hopes that even better ideas will emerge from the subsequent dialogue during the summer.

WOCE is probably the most complex and ambitious program that the world oceanographic community has ever attempted. The chief goal of WOCE is to make a quantum leap in the understanding and modeling of the ocean circulation so that its influence on the climate can be measured and predicted over years and decades. During its 10-year global study of the ocean spanning the 1990s, WOCE will employ major resources that are truly planetary in scale: satellites for measuring surface winds and sea surface elevations, fleets of ships for taking water samples and launching floats and drifters across the major oceans, a world wide network of stations for in situ sea level measurements, super computers for modeling and data management. Hundreds of scientists in dozens of countries are expected to participate.

The unique global data offered by satellites, coupled with thousands of in situ observations throughout the ocean, promises to offer the clearest "snapshot" of the ocean circulation ever taken. Take this unprecedented trove of data, massage it with mathematical models of great sophistication, and surely the ocean will reveal more of its secrets. In short, that is the plan and hope of WOCE.

Proposed U.S. contributions to WOCE are just as ambitious. U.S. scientists and resources are expected to play major roles in most aspects of the world experiment. Here are some of the implementation plan's key elements:

Satellite Missions. At least three satellite missions are planned for the early 1990s to obtain accurate global measurements of ocean topogra- phy, sea surface temperature, and surface winds. TOPEX/POSEIDON, a joint U.S.-French space mission scheduled for launch in 1991, will carry a U.S.-made precision altimeter for global sea level measurements for the mapping of geostrophic surface currents and their variability, as well as a French altimeter of new design. Japan's ADvanced Earth Observing Satellite (ADEOS), planned for launch in 1993, may carry a NASA scatterometer to measure worldwide surface wind velocities. Another altimeter and scatterometer are scheduled for launch in a polar orbit in 1990 aboard the European Space Agency's ERS-1. Still in the planning stage is a NASA mission to map the global gravity field and so improve our knowledge of the geoid. Combined with data still being generated by TIROS and other U.S. satellites, these missions are expected to provide an unprecedented database of crucial ocean measurements.

WOCE Hydrographic Programme. This worldwide experiment contemplates spending eight or nine years of ship time to take thousands of water samples in every ocean to measure the distributions of density, temperature, salinity and chemical tracers. The U.S. plan calls for contributions of ship time to the effort, and for U.S. funding of the international WHP project office, shipboard sampling equipment, and an accelerator mass spectrometer facility for radiocarbon analysis. U.S. scientists will participate in every phase of the program (scientific direction, shipboard sampling, shorebased chemical analysis, interpretation of results) and are expected to contribute a number of technology developments, including devising a new generation of small-volume water samplers and improving shipboard analyses of chlorofluoromethanes.

Global Surface Layer Program. Extensive studies of the ocean surface layer during WOCE will focus on investigations of surface velocity, surface layer transport, and surface layer heat flux and heat content. To support these studies, the U.S. plans a surface velocity (drifter) project, a volunteer ship project, and improved surface measurements for air-sea fluxes. The U.S. volunteer ship project will focus on the Atlantic and Pacific Oceans, where hopes are for deployment of up to 50,000 expendible instruments a year for measuring vertical profiles of temperature and. in some cases, conductivity. U.S. scientists also are developing new technology for measurements of surface meteorological parameters needed for 
improved estimates of air-sea fluxes. It is hoped that such improvements can be implemented for WOCE.

Velocity Measurement Programs. A key aspect of WOCE will involve direct measurements of the ocean currents using arrays of moored velocity meters, floats and drifters. The U.S. plan calls for U.S. funding of at least 2,400 surface drifters and a proposed office of buoy control, which would establish standards for WOCE drifters and plan the deployment and maintenance of a global drifter array. In addition, the plan proposes U.S. deployment of as many as 2,500 subsurface floats to map velocity and estimate eddy statistics. The plan also contemplates that U.S. scientists will be involved in velocity measurements at some 20 moored meter sites around the world.

Ocean Process Studies. A special set of field studies will be focused on one particular ocean the Atlantic. The rationale of international WOCE is that an intensive study of a single ocean basin should lead to major advances in eddy-resolving, basin-scale numerical models with realistic thermodynamics that can be extended to the global ocean. Here, U.S. scientists will have a leading role in carrying out experiments that examine subduction and three-dimensional circulation of the upper layers, deep circulation within the Brazil Basin, and mixing as studied via the dispersal of released tracers.

Sea Level Measurements. WOCE seeks to establish a network of stations around the world to record hourly sea level data. Such a system would aid in the reduction of altimetric errors from satellite missions and provide vital data for monitoring the variability of surface geostrophic currents. The U.S. plan would establish ten special sea level stations for use in the calibration of the TOPEX/POSEIDON altimeter data, further develop a network of new satellite-reporting sea level stations, and support a sea level data center in Hawaii to receive and process data from selected stations.

Ocean Circulation Modeling. Highly sophisticated numerical models are expected to become the primary tools for predicting changes in the global ocean circulation. A primary goal of WOCE is to develop models that simultaneously incorporate both eddy and thermodynamic processes. The U.S. plan calls for proposals in the general areas of model application and analysis, model development, and process and sensitivity studies. One element of the plan is a Community Modeling Effort (CME), which seeks to establish a series of baseline calculations of ocean processes for comparison with direct observations, beginning in the North Atlantic. Crucial to the modeling effort and to other aspects of WOCE are the calculations of air-sea exchanges that force the ocean circulation.

Data Management Systems. The U.S. plan is to establish a data network that would link all U.S. WOCE projects, yet protect the rights of scientists to the data they acquired as the field investigators. In keeping with the unified nature of WOCE and its products, the emphasis in data management efforts will be on providing all U.S. WOCE investigators with pertinent, quality-controlled data on a timely basis.

If the U.S. WOCE is funded at proposed levels, this will represent a new pool of monies allocated for the express purpose of studying the general circulation of the ocean. Funding for the U.S. program is expected from the National Science Foundation, the National Aeronautics and Space Administration, the Office of Naval Research, and the National Oceanic and Atmospheric Adminstration. Obviously, access to new funding avenues is one advantage that many scientists will see in participating in WOCE: more importantly, another is that the sharing of data and ideas gathered in a global study should offer some excellent opportunities for rapid progress in the advancement of knowledge.

The U.S. plan was developed within the context of the goals and objectives of international WOCE, which are presented in detail in the Scientific Plan for the WOCE, published in 1986 by the World Meteorological Organization. and the WOCE First Draft Implementation Plan, distributed in March, 1988 by the WOCE International Planning Office. The scientific rationale for projects and programs proposed in the U.S. plan is contained in a series of U.S. WOCE Planning Reports published over the last three years. Planning and implementation of U.S. WOCE has been directed by a Science Steering Committee (SSC) appointed by an interagency panel of the principal Federal funding agencies for WOCE: NSF, NASA, NOAA, and ONR. The NSF chairs the panel and is the lead agency for WOCE in the United States.

Members of the SSC are D. James Baker of Joint Oceanographic Institutions Inc., Russ Davis of Scripps Institution of Oceanography, Michael Freilich of Jet Propulsion Laboratories, Arnold Gordon of Lamont-Doherty Geological Observatory, Terry Joyce of Woods Hole Oceanographic Institution, James Ledwell of Lamont, Jim McWilliams of the National Center for Atmospheric Research, Worth Nowlin (chairman) of Texas A\&M University, James Price of Woods Hole, Lynne Talley of Scripps, Ray Weiss of Scripps, and Carl Wunsch of the Massachusetts Institute of Technology.

The review and comment period on the first draft U.S. implementation plan ends September 30,1988 . It then will be revised and presented in November at the WOCE International Scientific Conference in Paris. The U.S. SSC and funding agencies will consider the plan for final approval in January, and U.S. project proposals will be accepted beginning in mid-1989. A schedule of WOCE implementation activities is in the draft plan. Copies of the draft U.S. Implementation Plan are available from the U.S. Planning Office for WOCE, Department of Oceanography, Texas A\&M University, College Station, TX 77843. Comments about the plan also may be addressed to the planning office or via the WOCE.WIP mailbox on SCIENCEnet.

Contributed by Davis Mayes, U.S. WOCE Office, 6 May 1988
WOCE is

probably the

most complex

and ambitious

program that

the world

oceanographic

community has

ever attempted. 